ФЕДОТОВ Алексей Васильевич - соискатель Института социально-политических исследований Федерального научно-исследовательского социологического центра Российской академии наук (119333, Россия, г. Москва, ул. Фотиевой, 6, корп. 1; fedotovav@yandex.ru)

\title{
УСТОЙЧИВОСТЬ ФУНКЦИОНИРОВАНИЯ РЕГИОНАЛЬНОЙ СИСТЕМЫ ОБЩЕСТВЕННЫХ ОТНОШЕНИЙ КАК УСЛОВИЕ ОБЕСПЕЧЕНИЯ ЭФФЕКТИВНОСТИ ЭКОНОМИЧЕСКОГО РАЗВИТИЯ РЕГИОНА (на примере Республики Саха (Якутия))
}

\begin{abstract}
Аннотация. Автор рассматривает систему региональных межнациональных и межрелигиозных общественных отношений с точки зрения факторов, обеспечивающих ее стабильность. Ключевым условием эффективного экономического развития региона является устойчивость функционирования региональной системы общественных отношений.
\end{abstract}

Ключевые слова: национальная безопасность, устойчивое развитие, экономика региона, общественные отношения

$\mathrm{H}$ аселение России все настойчивее ставит перед властью вопрос о повышении уровня жизни населения, об увеличении финансирования социальной сферы, обеспечении справедливости в вопросах распределения материальных и иных благ, о равенстве всех групп и слоев общества перед законом, существенном ослаблении социального неравенства и повышении качества образовательных и медицинских услуг. Особенно отчетливо этот запрос выражается на региональном уровне, т.е. там, где власть непосредственно соприкасается с чаяниями людей и где ей приходится отвечать на злободневные вопросы активных и неравнодушных граждан [Ильичева, Лапин 2020: 439], в т.ч. отвечать за сохранение стабильности в системе межнациональных, межрелигиозных общественных отношений.

Эффективность экономического развития того или иного региона определяется способностью региональной системы устойчиво функционировать в условиях постоянно меняющейся внешней и внутренней среды. В этих условиях под социально-экономической стабильностью региона понимается согласованная работа всех элементов хозяйственной системы региона, приводящая к гармонизации социально-экономических интересов ее субъектов и направленная на качественные преобразования, обеспечивающие поступательный рост благосостояния и условий жизни каждого человека» [Голубева, Гладышева 2014: 32].

Региональная власть нуждается в стабильности и последовательности, в противном случае ее будущее становится весьма неопределенным [Ильичева, Лапин 2021: 19]. В этом смысле действующую в Республике Саха (Якутия) (далее - РС(Я)) систему межнациональных, межрелигиозных общественных отношений можно квалифицировать как стабильную. Об этом, в частности, свидетельствует то, что за минувшие два десятилетия в регионе не выявлены факты, подтверждающие причастность функционирующих на территории республики институтов гражданского общества, сформированных по этноконфессиональному принципу, к экстремистской, иной противоправной дея- 
тельности, признанной таковой на основании федерального закона «О противодействии экстремистской деятельности» ${ }^{1}$.

По данным систематических социологических исследований, в исторически сложившейся, относительно сбалансированной и ориентированной на толерантность региональной системе межэтнических и межконфессиональных обшественных отношений в РС(Я) продолжительное время наблюдается стабильность, устойчивость к соответствующим вызовам и угрозам, о чем, в частности, свидетельствуют и результаты этих социологических опросов. Один из таких опросов был проведен в 2019 г. Центром исследования межнациональных отношений Института социологии ФНИСЦ РАН совместно с учеными РС(Я) при поддержке республиканских органов, отвечающих за межнациональные отношения [Щеголькова 2019]. Целью опроса была оценка межнациональных отношений в республике, выявление случаев дискриминационных практик, а также отношение к представителям иной культуры.

По результатам опроса почти $80 \%$ респондентов оценили этноконфессиональные отношения в республике как доброжелательные, стабильные, с малой вероятностью конфликтов, а $83 \%$ опрошенных ответили, что не сталкивались со случаями дискриминации при приеме на работу, карьерном росте. При этом со случаями дискриминации по национальному признаку чаще всего сталкивались предприниматели (21\%), работники государственного аппарата (19\%), руководители предприятий и организаций (16\%), т.е. работники высококонкурентных сфер столкновения интересов основных взаимодействующих национальных групп республики [Щеголькова 2019]. Здесь важно отметить, что в районах компактного проживания коренных малых народов Севера (далее КМНC) среди занятых сельским хозяйством, подавляющая часть которых саха (якуты), о такой дискриминации не упоминалось вовсе.

Вместе с тем опросы показали, что конфликтный потенциал все же существует (на некоторое напряжение в межэтнических отношениях указали $34 \%$ респондентов, а на признаки взрывоопасности ситуации - 4\% опрошенных).

Фактор напряженности в межэтнических отношениях связан в первую очередь с трудовой миграцией, что более отчетливо проявляется в городах, в частности в Якутске (где по данным исследования около 1/3 респондентов отметили напряженность ситуации). Однако настороженное отношение к мигрантам высказывалось и в аналогичном опросе 2015 г.: тогда свыше 1/3 опрошенных допускали переезд мигрантов на постоянное местожительство в республику, $40 \%$ отметили положительное отношение жителей своего населенного пункта к приезжим, хотя 1/4 опрошенных были не согласны с этим ${ }^{2}$. При этом свыше $50 \%$ опрошенных утверждали, что на территории совместного проживания отношения с приезжими положительные, только 11,6\% утверждали обратное. Очевидно, что в этом случае неприятие вызывали не сами представители определенных этнических общностей, а страх перед наплывом мигрантов, опасение утратить свою привычную культуру и среду обитания ${ }^{3}$.

1 Федеральный закон от 25.07.2002 №114-Ф3 «О противодействии экстремистской деятельности» (редакция от 02.12.2019). -Российской газета (федеральный выпуск). 30.07 .2002 .

2 Информация по итогам 2015 года. О состоянии и развитии языков народов в Республике Саха (Якутия). - Официальный информационный портал Республики Саха (Якутия). Доступ: https://www.sakha.gov.ru/informatsija-po-itogam-2015-goda (проверено 15.07.2021).

3 Указ Главы Республики Саха (Якутия) от 25.10.2017 № 2166 «О государственной программе Республики Саха (Якутия) "Развитие гражданского общества и гармонизация межэтнических отношений в Республике Саха (Якутия) на 2018-2022 годы” . Доступ: https://glava.sakha.gov.ru/ot-25-oktyabrya-2017-g-----2166 (проверено 15.07.2021). 
Несколько более негативные оценки межнациональных отношений в 2019 г. в известной степени были спровоцированы событиями криминального характера, имевшими место в Якутске в марте 2019 г. и связанными с мигрантами киргизской национальности (отсюда неприязнь, выраженная в опросе респондентами к представителям Средней Азии, - $43 \%$ опрошенных, к приезжим в целом $-15 \%)^{1}$.

Тем не менее следует отметить, что опросы показывают благожелательное отношение друг к другу основных этнических групп в республике, в частности, русских и саха (якутов), но настороженное или даже враждебное отношение к трудовым мигрантам - $42 \%$ саха (якуты) и $23 \%$ русских [Шеголькова 2019].

Но интенсивное экономическое развитие РС(Я) все же требует притока рабочей силы, трудовой потенциал жителей, постоянно проживающих на территории республики, недостаточен. А это значит, что по мере расширения экономических программ региона нарастание притока трудовых мигрантов неизбежно. Без этого многие экономические проекты, реализуемые в регионе, по меньшей мере, замедлятся. Рост числа трудовых мигрантов так или иначе повышает уровень рисков возникновения конфликтных ситуаций на межнациональной и межконфессиональной основах.

Что послужило предпосылками межнационального конфликта с мигрантами киргизской национальности в марте 2019 г.? Можно выделить несколько составляющих, в т.Ч. экономический компонент.

1. Еще в советскую бытность РС(Я) по своей экономической направленности была разделена на аграрную часть региона, где преобладало коренное население - саха (якуты) и остальные КМНС республики, и индустриальную часть, где большинство составляли русские. По мере расширения индустриализации и информатизации общественного производства доля высокооплачиваемых мест в отраслях, занятых преимущественно коренным населением, становилась все меньше, а трудоустроиться в современные индустриальные отрасли общественного производства его представителям по разным причинам было затруднительно. Цифровизация экономики еще больше усложнила проблему трудоустройства КМНС, хотя предложения трудоустройства в промышленности, IT-сфере якутам, представителям КМНС постоянно поступают. Однако нередко они отказываются от них из-за того, что им очень сложно пересмотреть традиционный уклад жизни, ведь для этого нужно получать новую профессию, переучиваться, менять местожительство.

2. В 2017 г. в РС(Я) был установлен официальный запрет на привлечение в регион иностранцев (мигрантов), осуществляющих 14 видов трудовой и иной не запрещенной законом деятельности. В следующем, 2018 г., используя различные способы обхождения квотных ограничений, для занятия якобы легальной хозяйственной деятельностью в РС(Я) официально въехали 22,8 тыс. иностранных граждан, что больше квоты на временное проживание в 103 раза (!). С учетом уровня средней заработной платы (в разрезе видов хозяйственной деятельности за 2018 г.) фонд оплаты труда этих 22,8 тыс. иностранцев можно оценить в 17,3 млрд руб. Соответственно, одни только невыплаченные обязательные платежи в государственные внебюджетные фонды (Пенсионный фонд РФ, Фонд социального страхования РФ, Федеральный и территориальные фонды обязательного медицинского страхования) можно оценить в 5,2 млрд руб., что существенно повысило социальную нагрузку на региональный бюджет.

\footnotetext{
${ }^{1}$ Межнациональный конфликт в Якутии. - Политком.RU. 25.03.2019. Доступ: http:// politcom.ru/23332.html (проверено 15.07.2021).
} 
3. Существующие в республике механизмы социальной и культурной адаптации иностранных граждан и их интеграции в региональное общество дали сбой, причем это произошло в работе и структур публичной власти, и институтов гражданского общества 1 .

Острую фазу происшедшего конфликта удалось погасить, но риски возникновения межнациональных конфликтов сохраняются. Дальнейшее увеличение миграционного потока, достаточно сильная дифференциация в оплате труда коренных жителей, занятых преимущественно сельскохозяйственным трудом, и работников крупных добывающих предприятий, экологические проблемы, во многом обусловленные хищническим освоением природных ресурсов и ставящие под угрозу традиционные места обитания и виды деятельности коренных народов, - все это факторы с большой степенью вероятности могут обострить межэтнические проблемы в регионе, что, безусловно, негативно отразится и на его экономическом развитии. В связи с этим можно согласиться с исследователями этнических конфликтов в республике, что направленность негативного вектора этнонациональных установок в сторону приезжих говорит скорее о защитной реакции на ощущаемый миграционный приток, об «оборонительных» настроениях населения и о готовности в случае необходимости защищаться [Шеголькова 2019].

Для сохранения и упрочения межэтнической и межконфессиональной стабильности как условия эффективного экономического развития РС(Я) структуры публичной власти и институты гражданского общества вынуждены принимать меры по решению проблем, связанных с трудовой миграцией, оттоком трудоспособного местного населения из региона. Среди очевидных мер - привлечение инвестиций в региональную экономику, создание новых конкурентных, достойно оплачиваемых рабочих мест, борьба с сохраняющейся теневой экономикой. Однако важно делать это также с учетом ментальных установок, ценностных ориентаций коренного населения, широко пропагандируя позитивный опыт активной трудовой деятельности, благодаря которой работники, как представители местного населения, так и трудовые мигранты, обретают уверенность в будущем.

Анализируемая проблематика сохранения, упрочения межнациональной, межрелигиозной стабильности как необходимого условия эффективного экономического развития региона не ограничивается отношениями, которые складываются между якутами и русскими, с одной стороны, и мигрантами представителями дальнего и ближнего зарубежья - с другой. Эта проблематика охватывает все вопросы «встроенности» в хозяйственную систему РС(Я) как титульной нации (саха), так и КМНС республики, различных этносоциальноконфессиональных групп (например, казачества).

В связи с этим пристального внимания заслуживает проблематика бережного сохранения культурной самобытности, традиционного уклада хозяйственной деятельности КМНС РС(Я) в структуре экономики региона, которая рассматривается как особая область общественных отношений, переплетенных с менталитетом местных сообществ ${ }^{2}$.

Процесс сохранения традиционного уклада необходимо начинать со стимулирования у представителей КМНС, особенно у детей, интереса к изучению

1 Перцев А. «Люди у нас терпимые. До определенного момента». Почему в Якутии начались протесты против мигрантов. - Коммерсант Ђ. № 56/П. 01.04.2019.

2 Указ Главы Республики Саха (Якутия) от 13.12.2019 №892 «О государственной программе Республики Саха (Якутия) “Развитие Арктической зоны Республики Саха (Якутия) и коренных малочисленных народов Севера Республики Саха (Якутия) на 2020-2024 годы”». Доступ: https://docs.cntd.ru/document/561673168 (проверено 30.07.2021). 
родного языка, на котором выстроена накопленная веками система знаний. Этот процесс можно реализовать, в частности, за счет использования современных цифровых информационно-коммуникационных технологий, где особенно эффективны такие, как урок-путешествие по природным достопримечательностям РС(Я), урок-экскурсия, урок-викторина, дидактические игры, видеоролики, виртуальный музей, мультимедийные презентации с красочными средствами визуализации, обеспечивающими интерактивность, общение на родном языке, вызывающие положительные эмоции. Необходимо развивать и детскую литературу, издаваемую на языках КМНС республики, но для этого требуется финансовая поддержки публичными властями частных издателей, выпускающих такие детские издания ${ }^{1}$.

Однако ключевым фактором, который может активизировать участие представителей КМНС республики в процессе эффективного экономического развития региона, может стать приведение граждан в состояние сопричастности при совместном с властью определении уровня основных социально-экономических показателей развития республики [Ильичева, Кондрашов, Лапин 2021], что потребует от власти и общества формирования таких доверительных отношений, которые обеспечат всесторонний учет специфики экономического поведения коренных народов, их этносоциокультурных, религиозных, политических, мировоззренческих, когнитивных, институциональных особенностей.

Например, в традиционный сектор хозяйственной деятельности КМНС РС(Я) входят оленеводство, рыболовство, охотничий и ряд других народнохозяйственных промыслов, используемых для жизнеобеспечения представителей соответствующих народов (пошив одежды, изготовление мобильных жилищ, предметов быта, упряжи). Поэтому недопустимо тот же вылов ими рыбы сверх суточной нормы квалифицировать как браконьерство, т.к. рыба является жизненно необходимым продуктом питания представителей КМНС республики, особенно проживающих в сельских поселениях, ресурсной основой хозяйственной деятельности перерабатывающих предприятий региона, идет на экспорт. Развитие оленеводства, в свою очередь, играет этносохраняющую роль для КМНС республики, занимает важное место в традиционной культуре и мировоззрении их представителей.

Другой пример - периодически возникающие конфликты между представителями КМНС республики и вахтовиками - работниками крупных добывающих предприятий, которые могут приобретать национальную и религиозную окрашенность, заметно осложняя достижение целей эффективной региональной экономической политики, усиливая риск утраты контроля над развитием территории. Поэтому структуры публичной власти, промышленные группы, профильные институты гражданского общества, используя соответствующие ресурсы, должны постоянно прилагать значительные усилия для согласования своих действий с представителями этноэкономики, которые, в свою очередь, также вынуждены адаптироваться к внешнему влиянию, одновременно сохраняя свои ключевые типологические признаки [Деттер 2019: 37].

КМНС республики свойственно находиться практически в полном гомеостазе с окружающей средой: несмотря на суровость условий, природа дает им все необходимое для жизни. Освоение территорий их привычного проживания нарушает устоявшийся экологический баланс и вызывает протест со стороны

1 Предложения Марии Христофоровой поддержаны в Общественной палате России. Yakutsk.bezformata. 01.03.2020. Доступ: https://yakutsk.bezformata.com/listnews/mariihristoforovoj-podderzhani-v/73207360/ (проверено 15.07.2021). 
местного населения, т.е. в этот момент коренные народы становятся сдерживающим фактором для развития государства и компаний на данной территории. Происходит взаимная детерминация активности, направленной на сохранение баланса. Такая связь, вероятно, и предопределяет культурно-психологические особенности коренных народов и, соответственно, их экономическое поведение, позволяет сохранить приверженность традициям, земле предков, не используя в полной мере возможности, которые дает цивилизация [Деттер 2019: 37]. В таком контексте можно объяснить сравнительно высокий уровень бедности большей части представителей коренного населения Арктической зоны РС(Я), вызванной свойственными им непритязательностью, натурализмом, самодостаточностью, аскетизмом.

Таким образом, среди основных направлений формирования стабильной гармоничной системы межнациональных отношений можно выделить:

1) создание условий, способствующих динамичному социально-экономическому развитию всех этнических общностей, проживающих на территории РС(Я), особое внимание при этом должно быть уделено развитию КМНС республики;

2) разработку системы мер государственной поддержки институтов гражданского общества, чья деятельность нацелена на решение актуальных социально значимых проблем в сфере межэтнических и межконфессиональных отношений;

3) формирование благоприятных условий для адаптации и интеграции мигрантов (прежде всего, трудовых мигрантов) в единое экономическое и социально-культурное пространство РС(Я);

4) проведение мероприятий, в т.ч. с активным участием институтов гражданского общества, способствующих формированию доверительных отношений между властью и обществом, укреплению межэтнических и межрелигиозных отношений на основе ценностей многонационального общества, уважения ценностей традиционной культуры коренных жителей региона.

При этом следует учитывать и потенциальные риски нарушения стабильности межнациональных отношений в регионе. Это:

- увеличение потоков трудовой миграции из стран ближнего и дальнего зарубежья, возможные проблемы адаптации и интеграции мигрантов в экономическое и социально-культурное пространство РС(Я);

- возникновение противоречий в национальном самосознании коренных жителей республики и общероссийской гражданской идентичности;

- политизация национально-конфессионального фактора, использование традиционных верований КМНС в целях усиления их враждебности к другим народам и жителям республики, а также к нетрадиционным религиозным объединениям для содействия культурно-религиозной экспансии иностранных государств;

- уменьшение интереса малочисленных народов к изучению их самобытных языков, снижение интереса к национальной культуре, миграция из традиционных мест проживания в города;

- усиление миграционного оттока коренных жителей республики, среди которых много лиц с высшим образованием, высокообразованной молодежи, которые замещаются трудовыми мигрантами с низкой квалификацией, невысоким уровнем образования, что создает потенциальные конфликты в регионе.

Для сохранения, упрочения межнациональной, межрелигиозной стабильности как ключевого условия эффективного экономического развития региона структурам публичной власти, институтам гражданского общества следует активизировать работу по преодолению рисков, угроз, опасностей, связан- 
ных с имеющимися перекосами в становлении цифрового технологического уклада, формированию конкурентных, достойно оплачиваемых рабочих мест, чему мешает сохраняющаяся теневая экономика, недостаточный учет ментальных установок, ценностных ориентаций коренного населения, низкий уровень приспособленности мигрантов к традиционным укладам. Следует также усилить пропаганду позитивных практик такой трудовой деятельности, при которой представители местного населения и мигранты обретают общую уверенность в будущем.

\section{Список литературы}

Голубева Л.Ф., Гладышева А.В. 2014. Социально-экономическая стабильность региона как условие экономического роста. - Социально-экономические явления и процессы. Т. 9. № 4. С. 28-34.

Деттер Г.Т. 2019. Экономическое поведение коренных малочисленных народов Севера России: постановка проблемы. - Вестник Челябинского государственного университета. № 9(431). С. 32-42.

Ильичева Л.Е. Лапин А.В. 2020. Совершенствование процессов государственного управления России: формирование новой модели стратегий регионального развития. - Россия в XХІ веке: монография (под ред. Л.Е. Ильичевой, В.С. Комаровского). М.: Аспект-Пресс.

Ильичева Л.Е. Лапин А.В. 2021. Стратегии социально-экономического развития регионов в ракурсе национальных целей и приоритетов: Политический анализ: монография. М.: Аспект Пресс. 272 с.

Ильичева Л.Е., Кондрашов А.О., Лапин А.В. 2021. Доверие как мост над пропастью неуверенности между властью и обществом. - Мониторинг общественного мнения: экономические и социальные перемены. № 2(162). С. 162-185.

Щеголькова Е.Ю. 2019. Межнациональные (межэтнические) отношения (на примере Республики Саха (Якутия). - Информационно-аналитический бюллетень Института социологии ФНИСЦ РАН. № 1. С. 24-37.

\section{STABILITY OF THE FUNCTIONING OF THE REGIONAL SYSTEM OF PUBLIC RELATIONS AS A CONDITION FOR ENSURING THE EFFECTIVENESS OF THE ECONOMIC DEVELOPMENT OF THE REGION (on the example of the Republic of Sakha (Yakutia))}

Abstract. The author considers the system of regional interethnic and interreligious public relations from the point of view of the factors that ensure its stability. The key condition for the effective economic development of the region is the stability of the functioning of the regional system of public relations.

Keywords: national security, sustainable development, regional economy, social relations 